\title{
The Long-Term Impact of Household Wealth on Income Mobility
}

\author{
Kai Zhang, Dan Liu \\ JiNan University, Guangzhou, China \\ Email: zkzk4003@sina.com
}

How to cite this paper: Zhang, K. and Liu, D. (2017) The Long-Term Impact of Household Wealth on Income Mobility. Modern Economy, 8, 341-350.

https://doi.org/10.4236/me.2017.83024

Received: January 12, 2017

Accepted: March 3, 2017

Published: March 6, 2017

Copyright $\odot 2017$ by authors and Scientific Research Publishing Inc. This work is licensed under the Creative Commons Attribution International License (CC BY 4.0).

http://creativecommons.org/licenses/by/4.0/

\section{(c) (i) Open Access}

\begin{abstract}
By using the China Health and Nutrition Survey data, this paper targets the generation who enter the labor market at the age of 18 to 35 and tries to study the long-term impact of their family health on income mobility as well as keep track of the tendency. Three conclusions can be drown from the research. Firstly, the impact is more significant in the second poor group and the middle-income group than that in the high-income group, and that of the lowincome group is the worst. Secondly, in the long run, the impact shows a weakening trend, but the changing process is not the same. Thirdly, the significance of impact varies in different age groups. Compared with the groups aged 20 to 35 and 25 to 30 , the impact is relatively remarkable for those who just enter the labor market aged 18 to 25 .
\end{abstract}

\section{Keywords}

Household Wealth, Income Mobility, Long-Term Impact, Tendency

\section{Introduction}

In the late 20th century, China began to implement market economy system in order to carry out the two-track development strategy named planned and market economy. In the past 20 years, with the deepening of China's market economic reform, China has entered a stage of rapid development. But behind it, the wealth gap problem has also emerged. According to the data from the National Bureau of Statistics, China's Gini coefficient has been above the global average 0.44 since 2003. In 2008, it also lived up to 0.491. Although recent years have seen a certain degree of decline, the overall level is stable at around 0.47 , which is still higher than 0.4 , the internationally recognized warning line.

The widening wealth gap between the rich and the poor has a significantly negative impact on the economic development of the society. Firstly, the widen- 
ing wealth gap prevents economic development. It makes the centralization of wealth in the hands of the few, and increases the number of the poor, thereby causing insufficient consumption and enterprise overcapacity. Such phenomenon further exacerbated the enterprise competition, forcing the closure of a number of enterprises. Secondly, it will affect social harmony and stability. The polarization will lead to the increasing living pressure of the poor. For most of the underprivileged, their wealth has been plundered in disguise since their revenue growth can't ever keep up with inflation. And despite sparing no effort to make money, most immigrant workers still can not afford a house in a big city throughout their lives. In addition, the problems of health care, pension and children to school are hard to solve for the poor. This imbalance of living conditions between the rich and the poor may cause adverse psychological impact on the poor, initiating feelings of hatred for the rich. That is part of the reason why robbery, fraud and theft-prone occur frequently in recent years. Thirdly, the expansion of the gap will lead to class solidification, thus forming a vicious cycle. In the beginning of the reform and opening up, although the promotion of marketization caused the rich-poor division to some extent, the differentiation is still not so obvious since the absolute income gap is not large. But over time, this differentiation is getting clearer. The wealthy class, by virtue of its own capital advantage, achieves rapid accumulation of wealth while the poor is blocked in the way to do so. Society class gradually formed and consolidated itself. Such situation may be passed on generation by generation and in return further consolidates itself.

The causes of inequality vary, including historical factors, the transition of institution, industry income inequality, factor income inequality, and so elements. But the one which is more likely to be overlooked is position inequality when the youth enter the labor market. Actually, due to the impact of family wealth and background, young job seekers are not at the same starting line. Children from wealthy families have more choices, greater voice and more bargaining power. Therefore, at the beginning of one's career life, the youth from wealthy families tend to get higher wage than that from poor families. But over time, personal talent begins to take effect. Individual class begins to flow up or down. So how household wealth initially affects the flow of individual class in different income groups and what is the trend? For these problems, the paper will discuss indepth in the next few sections.

The following content is divided into five sections. The first part reviews the existed literatures about the research topic. The second part describes the empirical model and the variables used in this research. The third part introduces the data used. The forth part explains the empirical results. The final part summarizes some reasonable policy recommendations based on the empirical results.

\section{Literature Review}

Income mobility refers to the changing process of individual income class in the 
society over time, which shows either an upward trend or a downward trend. It is an important index to measure social justice and efficiency. In a relatively fair society, income mobility is higher since it can be decided by personal ability. On the contrary, in annot so fair society, because the wealthy occupy the highincome class by the virtue of their rights and status, people from the low-income class are hard to move upward. The income class gradually consolidates and leads to poor liquidity.

In other countries, study on income mobility began in the 1950s. It is Schumpeter [1] who leaded the pioneered research in this field and caused great impact. He proposed the concept of income mobility and compared it to hotel rooms which can be divided into three kinds: luxury, ordinary and simple. With the passage of time, guest in the hotel room will be changed: some people mayrise into better rooms, while others may fall into worse rooms. Subsequently, Friedman [2] also conducted a research on the mobility of income. He noted that in high income mobility society, social inequality is lower than that in low income mobility. After, Shorrocks [3], Hart [4], Atkinson [5], who studied on income mobility made some breakthroughs in the measurement methods, by improving the traditional measure indicators and proposing better measurement methods. Ever since the 21st century, study of income mobility began to refine. Some scholars compared the income mobility among different countries and studied the role of income mobility on income inequality.

Domestic research on income liquidity is limited by the lack of data. Since 2000, a number of scholars began the study successively, among which is Wang Haigang [6] who conducted earlier research in this area. He used the 1989-1997 CHNS data to calculate income mobility. His study showed that in the early 1990s income mobility promoted income equality in a way, but the effect got weakened significantly from the late 1990s. The grouping of samples also showed that income mobility can weaken income inequality of urban residents, but for rural and township residents, the effect is not so obvious. Yin Heng [7] studied the trend of income mobility by the use of CASS Distribution Project data in 1995 and 2002. The research found that compared with the late 1990s, the early 1990s has seen a substantial downward trend of urban population mobility. It is the time when practitioners with low education level, retirees and collective enterprise employees gradually fell into the bottom of income class, while the financial industry practitioners, staff of government departments and management personnel rised to the top of income class. The main reason is the market reform implemented in our country from 1991 to 1995, which had caused the rapid rise of the privileged groups and the falling of vulnerable groups. In the late 1990s, with the reform being steadily carried out, income class began to consolidate, accompanied by a substantial decline in mobility. Lei Xin and Chen Jiyong [8] used CHNS data to study income mobility and income inequality. They divided income mobility into three parts: growth, exchange and dispersion. The research results showed that growth of mobility helped reduce income inequality; exchange of mobility had a significantly negative effect on income in- 
equality; dispersion of mobility obviously expanded income inequality. Yan Binjian [9] conducted multi-dimensional measurement on income mobility with the 1986-2010 data from rural fixed observation point of the Ministry of Agriculture, to analyze the flowing situation of each income class and the factors affecting.

Through the above summary of existed literature, it can be found that most studies concentrate on estimation of income mobility during certain years or analyzing the changing trend. In addition, their samples were mostly researched as a whole. The innovation mainly lied in the calculation method and detailed analysis of mobility, instead of in-depth study for certain sample group. So this paper will offer a new perspective: the target subjects will be limited to those who just enter the workplace at the age of 18 to 35, a group with strong income mobility. By observing mobility changes of these young people, this paper will study how the variable of household wealth influence income mobility.

There are three innovations of the research. Firstly, this article uses a new method to measure household wealth. Unlike the conventional approach, the statistical method of principal component analysis is applied to analyze the variables of family living environment, transport tools and fixed assets, so as to pull out the comprehensive index of household wealth. Secondly, we study the effect of household wealth on the mobility of different income classes and track their long-term trends. Thirdly, the samples are grouped by age, so we can observed how the variable of household wealth take effect in different age groups.

Through the research, three conclusions are drown. Firstly, household wealth has a significant positive impact on the mobility of middle and lower income groups, particularly those who are in the income interval of $20 \%-40 \%$. Secondly, the impact of household wealth on individual income mobility will diminish over time. Finally, compared with the other two groups, the effect of household wealth on income mobility is more obvious for people aged 18 to 25 .

\section{Model}

The main content of this paper is the impact of household wealth on income mobility. Here we define household wealth as the wealth background of one's family in a certain period. The previous literature tend to use the average family income to proximately measure the variable of household wealth. In this paper, we use a new measurement method instead. By using the principal component analysis method, the variable of household wealth will be drown from three factors: living environment, transportation, household fixed assets. The measurement range of these three factors are as below: living environment involves the way to drink, the fuel used for cooking and the type of toilet; transportation includes the kind of vehicle used, the total number and the value; fixed assets comprise the home appliances used including color TV, air conditioner, washing machine, refrigerator, camera, rice cooker, telephone, VCD and other assets. By this method, we can accurately and specifically grasp the real situation of one's household wealth. 
The empirical model used in this paper is multiple regression with the household wealth as the explanatory variable and income mobility as the interpreted variable. Income mobility will be measured by the change of rank: the income is ranked from high to low and divided into 10 grades. The value of income mobility is measured by the balance of income grade between certain years. For example, if one's income is in 3th grade in 2000, but 6th grade in 2004, then his income mobility is 3 . Conversely, if he falls into 1 th grade in 2004, then his income mobility is -2 .

In this research, several variables are controlled including the age, the sex, the marital status and the occupation type. And here we have 8 occupation types including government agency and research institute, state-owned enterprises, small groups (such as township-owned), large group (county, city and province-owned), family contract farming, private and individual enterprises, foreign funded enterprise (owned by foreigners, overseas Chinese and joint venture).

\section{Data}

The data used in this article is from China Health and Nutrition Survey data which is obtained from a joint investigation by the population research center of the North Carolina University, the national institute of nutrition and physical security and the Chinese center for disease control and prevention. The survey data covers nine times of investigation from 1989 to2011: 1989, 1991, 1993, 1991, 2000, 2004, 2006, 2009 and 2011 respectively, with each survey interviewing about 220 urban and rural communities (including the urban neighborhood committees and rural villages), and about 20 families each community, namely about 4400 families in total. Covered provinces include Liaoning, Heilongjiang, Jiangsu, Shandong, Henan, Hubei, Guangxi and Guizhou, 8 provinces (autonomous regions included) in total. The multi-stage cluster sampling method is used to do the survey. CHNS data has the advantage of wide coverage of province, large sample size and long time period. It also contains rich indexes involving family information and individual characteristics. Therefore it is widely used in the research on income mobility.

According to the research, the selection of main variables contains fixed assets of the family, health status, the sex, the age, the occupation, etc. The survey time ranges from 2000 to 2011, during which a total of five researches were conducted. However, due to the adjustment of sample data in 2000, part of the samples lose continuity before and after 2000, and the problem of data missing is serious in some variables before 2000. After comprehensive consideration, this article used the data from 2000 to 2011 instead. Samples are selected in the young generation who are at the age of 18 to 35 . These people are so representative since they just enter the workplace and have stronger reliance on household wealth. To some extent, their income flows are influenced by family wealth.

After the merge of data and excluding the missing and outlier ones, the remaining sample size is 2288 covering five continuous years. Descriptive statistics about the sample is seen in the Table 1: Young and middle-aged people are in 
Table 1. Descriptive statistics.

\begin{tabular}{cccccc}
\hline variable & $\mathrm{N}$ & $\max$ & $\min$ & mean & sd \\
\hline gender & 2288 & 1 & 0 & 0.526 & 0.499 \\
age & 2288 & 35 & 18 & 26.43 & 4.949 \\
married & 2288 & 1 & 0 & 0.593 & 0.491 \\
work s e & 1897 & 9 & 1 & 4.018 & 1.550 \\
wealth $\sim \mathrm{x}$ & 1942 & 1.000 & 0.001 & 0.323 & 0.254 \\
income $\sim \mathrm{t}$ & 1539 & 87600 & -1200 & 5005 & 6842 \\
\hline
\end{tabular}

majority with average age of 26.43. From the point of gender, the sample size of men is 1203 while that of women is 1085 , showing little difference. As for the structure of marriage, marriaged people make the most percentage. And for household wealth index, since most people are from poor families, the average level of household wealth is relatively low at 0.323 .

\section{Empirical Analysis}

In this part, we apply the method of principal component analysis to measure the household wealth. Unlike the previous literature in which the household wealth is measured only by household income, this article selects three factors: family living environment, transportation and fixed assets, in order to extract a comprehensive index of household wealth. Through the principal component analysis of the variables, it's found that the lambdas of the three factors are over 1: $6.41,1.14,1.04$, and their explanatory powers are $53.4 \%, 9.5 \%$ and $53.4 \%$ respectively. Then the household wealth index is derived from weighting and standardizing the three factors above. As the results show, the household wealth index explains more than $70 \%$ of the household wealth. In this paper, income mobility will be measured by the change of rank: the income is ranked from high to low and then divided into 10 grades. Therefore the value of income mobility is measured by the balance of income grade between certain years. For example, if an individual income is in 3th grade in the first year, 5th grade in the second year, then his income mobility is 1 in the second year. Conversely, if he falls into 1 th grade in the second year, then his income mobility is -2 . Here we choose the year 2000 as the base year, the income mobility from the year 2000 to 2004, 2006, 2009,2011 is measured respectively.

After the measurement of the household wealth and the income mobility, the empirical research is carried on in accordance with the preceding model. First of all, according to the income level, the samples in 2000 are divided into four groups: $0-20 \%, 20 \%-40 \%, 40 \%-60 \%, 40 \%-60 \%$, in order to study the effect of household wealth on income mobility in different income class and observe their long-term trend. Secondly, the samples are divided into three groups by age: $18-24,24$ to $30,30-35$, to study the influence of household wealth on income mobility in different age periods. 


\subsection{Grouping Regression of Different Income Levels}

The results are shown in the Table 2 below from vertical and horizontal dimensions. Horizontally, the income is divided into four groups from high to low, 0 $20 \%, 20 \%-40 \%, 20 \%-60 \%, 60 \%-80 \%$. Vertically, the time period is divided into 2000-2004, 2004-2006, 2000-2009, 2009-2000 four groups. It can be found from the regression that in most cases, household wealth has a significantly positive effect on income mobility, but the impact is not the same for each group. From the horizontal view, there is no obvious effect on the income mobility for those whose household wealth is in the interval of $60 \%-80 \%$, but for those in the interval of $20 \%-40 \%$ and $40 \%-60 \%$, the effect is obvious with the impact factor being 3.65 and 3.57 respectively. And in the group of $0-20 \%$, the effect is weaker with the impact factor being 2.239. The main cause of this result may be that since the high income group possess a well-off family background and people from low-income families tend to be poor in quality and capability, it is limited to upgrade their income level merely by improving the household wealth. However, for the second poor and middle-income class with certain human capital accumulation, the household wealth improvement can reduce the family burden and help them rise quickly to the higher income class.

In terms of the long-term effect, it can be seen from the table that the effect of group 4 is stable, while the other three groups show a long-term downward trend. As for group 1, although the effect rise slightly in 2006, it still shows a downward trend in the long run. For group 2, the coefficient falls slowly at first, but keeps at 2.082 in 2011, which states that the effect of household wealth on income mobility is relatively stable. For group 3, the coefficient drops quickly to merely 1.456 in 2011, which is 1.403 larger than group 1 . The main cause of this result may be that since people from group 3 are in wealthy family, the effect may diminish with the pass of the time while the effect of group 2 stays more stable. In addition, due to the poor family economic condition which leads to lower personal quality, the effect of household wealth is not as big as that of group 2 and group 3.

\subsection{Grouping Regression of Different Age Groups}

To study the effect of household wealth on individual income mobility of different ages, the sample are divided into three groups by age: 18 - 25, 25 - 30, 30 35. As the regression results show in the Table 3 , household wealth has significant positive influence on income mobility for the samples who are at the age of 18 to 25 , seen from the coefficient value being1.502. However, for those who are aged 25 to 30, the effect is not so obvious.And the coefficient value appears to be even negative for those aged 30 to 35 .The reason may be that people at this age of 18 to 25 are just entering the labor market, having strong dependence on household wealth. Better household wealth condition can reduce the economic burden of these young people and offer them stronger bargaining power to upgrade their income level. But with the increase of age, these young people start to earn their own livings, while their personal competition ability begin to take 
Table 2. Regression of different income levels.

\begin{tabular}{|c|c|c|c|c|c|}
\hline time & variable & (1) & (2) & (3) & (4) \\
\hline \multirow{10}{*}{$2000-2004$} & wealth_index & $2.239^{* * *}$ & $3.650^{* * *}$ & $3.573^{* * *}$ & 0.543 \\
\hline & & $(3.92)$ & $(6.82)$ & (6.08) & $(0.34)$ \\
\hline & married & -0.325 & -0.654 & -0.280 & -0.146 \\
\hline & & $(-0.87)$ & $(-1.24)$ & $(-0.50)$ & $(-0.07)$ \\
\hline & age & 0.0103 & -0.0244 & -0.0280 & 0.190 \\
\hline & & $(0.40)$ & $(-0.68)$ & $(-0.68)$ & $(1.72)$ \\
\hline & gender & 0.0731 & 0.386 & 0.118 & -0.246 \\
\hline & & $(0.35)$ & $(1.44)$ & $(0.39)$ & $(-0.29)$ \\
\hline & $\mathrm{N}$ & 347 & 243 & 246 & 51 \\
\hline & R2 & 0.044 & 0.187 & 0.136 & 0.069 \\
\hline \multirow{12}{*}{ 2000-2006 } & adj. R2 & 0.033 & 0.173 & 0.122 & -0.011 \\
\hline & wealth_index & $2.508^{\star * *}$ & $2.531^{\star * *}$ & $3.169^{* * *}$ & 2.377 \\
\hline & & $(3.50)$ & $(4.38)$ & $(5.49)$ & $(1.41)$ \\
\hline & married & 0.155 & -0.752 & $-1.463^{*}$ & 1.989 \\
\hline & & $(0.28)$ & $(-1.27)$ & $(-2.29)$ & $(0.71)$ \\
\hline & age & 0.0407 & 0.0401 & 0.0215 & -0.0466 \\
\hline & & $(1.21)$ & $(1.04)$ & $(0.55)$ & $(-0.39)$ \\
\hline & gender & $1.010^{\star * *}$ & $0.627^{\star}$ & 0.555 & -0.512 \\
\hline & & $(3.76)$ & $(2.11)$ & $(1.87)$ & $(-0.55)$ \\
\hline & $\mathrm{N}$ & 292 & 218 & 230 & 43 \\
\hline & $\mathrm{R} 2$ & 0.083 & 0.100 & 0.146 & 0.085 \\
\hline & adj. R2 & 0.070 & 0.083 & 0.130 & -0.011 \\
\hline \multirow{11}{*}{ 2000-2009 } & wealth_index & $1.446^{\star}$ & $2.529^{\star * *}$ & $2.703^{\star * *}$ & 0.955 \\
\hline & & $(2.31)$ & $(4.38)$ & $(5.23)$ & $(0.61)$ \\
\hline & married & -0.237 & 0.554 & -0.0507 & 2.623 \\
\hline & & $(-0.36)$ & $(0.78)$ & $(-0.07)$ & $(1.31)$ \\
\hline & age & 0.0142 & -0.0246 & -0.0336 & 0.0625 \\
\hline & & $(0.51)$ & $(-0.69)$ & $(-0.90)$ & $(0.57)$ \\
\hline & gender & $0.673^{\star \star}$ & 0.568 & $0.706^{\star}$ & 0.413 \\
\hline & & $(2.99)$ & $(1.92)$ & $(2.51)$ & $(0.47)$ \\
\hline & $\mathrm{N}$ & 307 & 231 & 235 & 45 \\
\hline & R2 & 0.043 & 0.101 & 0.133 & 0.079 \\
\hline & adj. R2 & 0.030 & 0.085 & 0.118 & -0.013 \\
\hline \multirow{11}{*}{$2000-2011$} & wealth_index & $1.403^{\star}$ & $2.082^{\star * *}$ & $1.456^{\star *}$ & 1.212 \\
\hline & & $(2.16)$ & $(3.90)$ & (2.69) & $(0.62)$ \\
\hline & married & 0.462 & 0.878 & 0.323 & 0 \\
\hline & & $(0.54)$ & $(1.29)$ & $(0.47)$ & (.) \\
\hline & age & -0.0525 & -0.0166 & -0.0778 & -0.0242 \\
\hline & & $(-1.78)$ & $(-0.47)$ & $(-1.96)$ & $(-0.16)$ \\
\hline & gender & $0.498^{\star}$ & 0.503 & 0.529 & -0.536 \\
\hline & & $(2.04)$ & $(1.84)$ & $(1.87)$ & $(-0.53)$ \\
\hline & $\mathrm{N}$ & 280 & 223 & 225 & 40 \\
\hline & R2 & 0.045 & 0.086 & 0.065 & 0.026 \\
\hline & adj. R2 & 0.031 & 0.069 & 0.048 & -0.056 \\
\hline
\end{tabular}

Note: $t$ statistic regression coefficients are shown in brackets; ${ }^{*},{ }^{* *},{ }^{* * *}$ respectively represents the significance level of $10 \%, 5 \%$ and $1 \%$. 
Table 3. Regression of different age groups.

\begin{tabular}{cccc}
\hline varibale & $(1)$ & $(2)$ & $(3)$ \\
\hline wealth_index & $1.502^{*}$ & 0.935 & -0.258 \\
& $(1.79)$ & $(1.17)$ & $(-0.44)$ \\
married & -0.264 & 0.146 & -0.302 \\
& $(-0.56)$ & $(0.18)$ & $(-0.29)$ \\
age & -0.0468 & 0.125 & 0.0341 \\
& $(-0.41)$ & $(0.98)$ & $(0.35)$ \\
gender & -0.410 & -0.226 & -0.0510 \\
& $(-0.91)$ & $(-0.62)$ & $(-0.18)$ \\
work_style & -0.0759 & -0.0317 & -0.145 \\
& $(-0.68)$ & $(-0.29)$ & $(-1.68)$ \\
N & 138 & 212 & 303 \\
R2 & 0.045 & 0.016 & 0.011 \\
adj. R2 & 0.009 & -0.008 & -0.006 \\
\hline
\end{tabular}

Note: $\mathrm{t}$ statistic regression coefficients are shown in brackets; ${ }^{*},{ }^{* *},{ }^{* * *}$ respectively represents the significance level of $10 \%, 5 \%$ and $1 \%$.

hold. Therefore, their dependence on household wealth gradually gets weakened with aging. As for those aged 25 to 30 and 30 to 35 , the result show that household wealth has no significant impact on income mobility.

\section{Conclusions and Policy Recommendations}

The research objects of this article are people who are at the age of 18 to 35 in the year 2000. The influence of household wealth of this generation on income mobility is studied and the long-term trend is traced. Through the research, we draw three main conclusions: Firstly, the impact is more significant in the second poor group and the middle-income group than that in the high-income group, and that of the low-income group is the worst. Secondly, in the long run, the impact shows a weakening trend, but the changing process is not the same. Thirdly, the significance of impact varies in different age groups. Compared with the groups aged 20 to 35 and 25 to 30 , the impact is relatively remarkable for those who just enter the labor market aged 18 to 25 .

Based on the empirical results, this article puts forward two suggestions for improvement in the relative policy: First of all, we should pay attention to the cultivation of quality and ability in children, especially those from poor families, in order to improve their personal competitiveness in the labor market in the future. Secondly, the relevant department is responsible to provide the disadvantaged groups with certain subsidies so as to reduce their family burden and help them gain stronger bargaining power in the labor market.

There are two improvements in the research: Firstly, the phenomenon of missing data in some variables in CHNS data is relatively serious, which leads to sample inadequacy and lack of representativeness. Secondly, the research is 
conducted in a discrete period of time: 2000-2004, 2000-2006, 2006-2009, 20002000. For the above two drawbacks, there is a need for a more detailed research in the case of finding out more integral data.

\section{References}

[1] Schumpeter, J. (1955) Imperialism and Social Classes. Meridian Books, New York.

[2] Friedman, M. (1962) Capitalism and Freedom. University of Chicago Press, Chicago.

[3] Shorrocks, A. (1978) Income Inequality and Income Mobility. Journal of Theory, 19, 376-393.

[4] Hart, P. (1976) The Comparative Statics and Dynamics of Income Distributions? Journal of the Royal Statistical Society, 139, 19-42. https://doi.org/10.2307/2344387

[5] Atkinson, A., Bourguignon, F. and Morrison, C. (1992) Empirical Studies of Earnings Mobility. Harwood Academic Publishers.

[6] Wang, H.G. (2005) The Household Income Mobility and Its Equalizing Long-term Income in China. Economic Research Journal, F126.2.

[7] Yin, H., Li, S. and Deng, Q.H. (2006) Income Mobility in Urban China. Economic Research Journal, F124.7.

[8] Lei, X. and Chen, J.Y. (2012) Income Mobility and Income Inequality: Empirical Study Based on CHNS Data. The Journal of World Economy.

[9] Yan, B.J., Zhou, Y.H. and Yu, X.H. (2014) A Study on Rural Household Per Capita Income Fluidity in China. China Economic Quarterly.

Submit or recommend next manuscript to SCIRP and we will provide best service for you:

Accepting pre-submission inquiries through Email, Facebook, LinkedIn, Twitter, etc. A wide selection of journals (inclusive of 9 subjects, more than 200 journals) Providing 24-hour high-quality service User-friendly online submission system Fair and swift peer-review system Efficient typesetting and proofreading procedure Display of the result of downloads and visits, as well as the number of cited articles Maximum dissemination of your research work

Submit your manuscript at: http://papersubmission.scirp.org/

Or contact me@scirp.org 